ISSN 1991-8631

Original Paper

http://indexmedicus.afro.who.int

\title{
Extraction assistée par enzyme du jus de la pulpe frâiche du rônier (Borassus aethiopum Mart.) acclimaté au Benin : caractérisation physico-chimique et microbiologique
}

\author{
Euloge S. ADJOU, Hospice AMAMION, Fidèle P. TCHOBO, Vahid M. AISSI et \\ Mohamed M. SOUMANOU *
}

Unité de Recherche en Génie Enzymatique et Alimentaire, Laboratoire d'Etude et de Recherche en Chimie Appliquée. Ecole Polytechnique d'Abomey-Calavi, Université d'Abomey-Calavi, Bénin, 01 BP 2009 Cotonou, République du Bénin.

*Auteur correspondant,E-mail: msoumanoufr@yahoo.fr,mohamed.soumanou@epac.uac.bj

\section{RESUME}

Dans cette étude, deux enzymes de type pectinases (Klerzyme 120 et Rapidase press) ont été utilisées pour l'extraction du jus de la pulpe fraîche de rônier. L'évaluation des conditions optimales d'extraction a permis d'obtenir les meilleurs rendements à $50{ }^{\circ} \mathrm{C}$ après $120 \mathrm{~min}$ d'incubation. Ces rendements sont respectivement de 79,8\% et 78,4\% pour le jus extrait avec la Rapidase press et la Klerzyme120. L'évaluation des caractéristiques physico-chimiques et nutritionnelles à savoir le $\mathrm{pH}$, l'acidité titrable, la teneur en matière sèche, les teneurs en sucres totaux, en caroténoïdes, en vitamine $\mathrm{C}$ et en sels minéraux ont permis de mettre au point une fiche technique (diagramme) de production du jus de rônier à base d'enzyme (pectinase). La détermination des paramètres microbiologiques des jus a montré que le barème de pasteurisation appliqué est efficace avec une absence totale d'espèces pathogènes. Les jus obtenus sont très odorants et conservent l'arôme caractéristique du fruit.

(C) 2013 International Formulae Group. All rights reserved.

Mots clés: Rônier, extraction, enzyme, jus, pectinase, caractérisation.

\section{INTRODUCTION}

La faim et la malnutrition demeurent un fléau mondial et touchent près de huit cent millions de personnes dont la majorité se trouve dans les pays en développement où la notion de sécurité alimentaire reste un luxe (FAO, 1994). Dans ces pays, l'agriculture connaît une stagnation et l'aide alimentaire est toujours d'actualité, avec un taux de croissance démographique en plein essor $(2,9$ à $3,9 \%$ en 2025). Pour contribuer à la lutte contre l'insécurité alimentaire, on devrait accroître la production agricole et valoriser les produits locaux grâce à l'utilisation judicieuse des connaissances techniques et des outils biotechnologiques. La valorisation des fruits tropicaux à travers leur biotransformation à l'aide d'enzymes en différents produits mieux conservés et à valeur ajoutée en est un exemple.

La flore africaine riche et variée comporte plusieurs plantes forestières dont notamment le genre Borassus qui présente une large distribution en Afrique de part et d'autre 
de l'équateur (Ezoua et al., 1999). Il comporte plusieurs espèces dont une nouvelle espèce fut encore récemment découverte au Burkina Faso (Bayton et al., 2006). Parmi ces espèces, la plus importante est le rônier (Borassus aethiopum Mart.). Ce palmier est beaucoup utilisé par la pharmacopée traditionnelle à cause de ses vertus thérapeutiques et pour les revenus importants tirés de la commercialisation de ses feuilles et racines (Houankou, 2005). De plus, il est également sollicité pour la production de vin de palme et l'utilisation du stipe dans la construction (Houankou, 2005), ce qui conduit malheureusement à la mort de l'arbre.

Les fruits pulpeux, rose-orangés à maturité et très odorants sont quant à eux abandonnés par la population béninoise à cause de leur richesse en fibres résistantes qui rendent difficile toute transformation semiindustrielle. Ces fruits sont par conséquent perdus chaque année en quantités importantes. Les travaux d'Ali et al. (2010) réalisés sur les fruits de rônier récoltés au Cameroun, indiquent que la pulpe du rônier est riche en sucres totaux, ce qui rend difficile sa conservation à cause des problèmes de fermentation. De même, sa teneur en eau relativement élevée (supérieure à celle de la banane) le prédispose à de profonds changements après la récolte et pourrait justifier les pertes importantes observées chaque année (Ezoua et al., 1999). Cependant, ses teneurs en caroténoïdes et en vitamine C sont très élevées, ce qui l'indique comme une source importante de vitamines A et C (Ali et al., 2010). La pulpe est également riche en minéraux comme le calcium, le magnésium et le phosphore (Ali et al., 2010).

Afin de tirer profit de cette ressource peu coûteuse, potentiellement intéressante et pratiquement inexploitée, le présent travail vise à étudier l'extraction du jus de la pulpe fraîche du fruit de rônier au moyen de deux types d'enzyme à activité pectinolytique, notamment la Rapidase press et la Klerzyme 120, à déterminer les caractéristiques physicochimique, microbiologique et organoleptique des jus obtenus et à étudier leur stabilité. La présente étude vise également à compenser le déficit d'informations sur le rônier et à mettre à la disposition des industriels une technologie appropriée de production du jus à partir des fruits mûrs de rônier.

\section{MATERIEL ET METHODES Matériel végétal}

Le matériel végétal utilisé est constitué des fruits mûrs de Borassus aethiopum Mart., rose-orangés, très odorants, fermes au toucher et pesant entre 1,6 et 1,8 kilogramme. Ces fruits sont récoltés dans la région de Pahou située au sud du Bénin et dans le département de l'Atlantique.

Les enzymes de type pectinases utilisées dans la présente étude sont des enzymes pures liquides (Rapidase press et la Klerzyme 120) commercialisées par la société DSM Food Technologie (France).

\section{Méthodologie d'extraction}

Les fruits réceptionnés sont triés selon leur aspect et seuls les fruits mûrs, roseorangés et fermes au toucher sont retenus. Ils sont ensuite lavés, épluchés puis dépulpés. Les pulpes sont ensuite découpées en petits morceaux puis écrasées à l'aide d'un moulin électrique. Environ $5 \mathrm{~kg}$ de purée obtenue sont préchauffés entre $45-50{ }^{\circ} \mathrm{C}$ puis refroidis à 35 ${ }^{\circ} \mathrm{C}$. L'enzyme est ensuite ajoutée à une concentration de $1 \mathrm{ml} / \mathrm{kg}$ de pulpe. Les pulpes ainsi traitées sont homogénéisées, puis incubées à $30,40,50$ et $60^{\circ} \mathrm{C}$ pendant 30,60 et $120 \mathrm{~min}$ avec une macération intermittente. Deux lots de pulpes sont constitués. Le premier est incubé en présence de Rapidase press et le second est incubé en présence de klerzyme120. Un témoin est réalisé sans addition d'enzyme. Les jus sont ensuite extraits par pressage à l'aide d'une presse mécanique (Figure 1).

Les rendements d'extraction sont ensuite calculés dans chaque cas en utilisant la formule suivante :

$$
\text { Rendement }(\%)=\frac{\text { Masse de jus obtenue }}{\text { Masse de pulpe traitée }} \times 100
$$




\section{Technique de stabilisation}

Les jus de fruits étant en général très peu stables à cause de leur teneur en sucres totaux et de leur richesse en éléments nutritifs, il est donc indispensable qu'ils fassent l'objet d'un traitement technologique (l'utilisation de conservateur étant interdite), afin de posséder une stabilité à long terme. Dans cette étude, les essais de stabilisation sont effectués sur des jus produits au moyen de Rapidase press à une température de $50{ }^{\circ} \mathrm{C}$ après $120 \mathrm{~min}$ d'incubation.

La technique de stabilisation utilisée est une pasteurisation en flash. Elle consiste à effectuer un remplissage des bouteilles en verre avec le jus et à les porter à $92 / 98{ }^{\circ} \mathrm{C}$ pendant $15 \mathrm{~min}$. Les bouteilles après fermeture subissent ensuite une appertisation et un refroidissement lent (Figure 2). Il faut noter qu'avant la "flash pasteurisation" le jus est préchauffé à $50^{\circ} \mathrm{C}$.

\section{Caractérisations physico-chimique et nutritionnelle}

La détermination du $\mathrm{pH}$ des jus est effectuée par une mesure directe à l'aide d'un pH-mètre préalablement étalonné de type Shott Gerate CG820. L'acidité titrable des jus, exprimée en teneur d'acide citrique par unité de volume est déterminée par titrimétrie à l'aide d'une solution d'hydroxyde de sodium $0,01 \mathrm{~N}$, en présence de phénolphtaléine comme indicateur coloré (Ezoua et al., 1999) (Tableau 1). La matière sèche des jus est déterminée par étuvage à $105^{\circ} \mathrm{C}$ jusqu'à obtention d'un poids constant (AOAC, 1990). Les cendres totales sont déterminées par incinération, après un étuvage à $105{ }^{\circ} \mathrm{C}$ pendant 24 heures des échantillons suivi par une calcination au four à moufle pendant 1 heure à $600{ }^{\circ} \mathrm{C}$ (AOAC, 1990). Le dosage des sucres totaux est réalisé par spectrophotométrie selon la méthode au phénol-acide sulfurique (Ezoua et al., 1999). La teneur en caroténoïdes des jus est déterminée par spectrophotométrie à $436 \mathrm{~nm}$ selon la méthode AOAC (1990). La détermination de la vitamine $\mathrm{C}$ a été réalisée par un dosage en retour en présence de diiode et de thiosulfate de sodium selon la méthode décrite par Pourmaghi-Azar et Ojani (1997). Le dosage des sels minéraux dans les jus obtenus est réalisé par la méthode NF 14082 décrite comme suit : $3 \mathrm{~g}$ de jus sont pesés dans un creuset en porcelaine que l'on porte au four à $450{ }^{\circ} \mathrm{C}$ jusqu'à calcination. Les cendres issues de la calcination sont ensuite dissoutes dans une solution de $5 \mathrm{~mL}$ d'acide chlorhydrique $(2 \mathrm{~N})$ et la nouvelle solution obtenue est enfin évaporée jusqu'à siccité. On obtient alors un résidu final qui est à nouveau dissout dans une solution d'acide nitrique de concentration $0,1 \mathrm{~mol} / \mathrm{L}$ et la teneur en sel minéraux est déterminée par spectrophotométrie d'absorption atomique.

\section{Analyses microbiologiques \\ Numération de la flore totale}

La flore totale est déterminée par ensemencement des dilutions décimales en double sur la gélose «Plate Count Agar» (PCA). L'incubation a été effectuée à $30{ }^{\circ} \mathrm{C}$ pendant $48 \mathrm{~h}$; puis le dénombrement et la moyenne des germes en Unité Formant Colonie (UFC)/ml d'échantillon de jus analysé ont été faits selon la méthode spécifiée par la norme NF ISO 4832.

\section{Numération des levures et moisissures}

Des aliquotes de $0,1 \mathrm{ml}$ de jus et de ses dilutions décimales ont été ensemencées en surface sur la gélose Sabouraud au Chloramphénicol, initialement préparée et coulée dans des boîtes de pétrie de $9 \mathrm{~cm}$ de diamètre. Le dénombrement des colonies blanches ou colorées, lisses et crémeuses de levures et des moisissures sous forme poudreuse a été effectué après 5 jours d'incubation à $25^{\circ} \mathrm{C}$ selon la norme NF ISO 7954.

\section{Recherche des coliformes totaux et fécaux}

Les coliformes totaux sont recherchés selon la méthode NPP décrite par la norme NF ISO 4831. La recherche des coliformes thermotolérants est effectuée par comptage des colonies obtenues à $44{ }^{\circ} \mathrm{C}$ selon la méthode spécifiée par la norme NF V 08-060. 


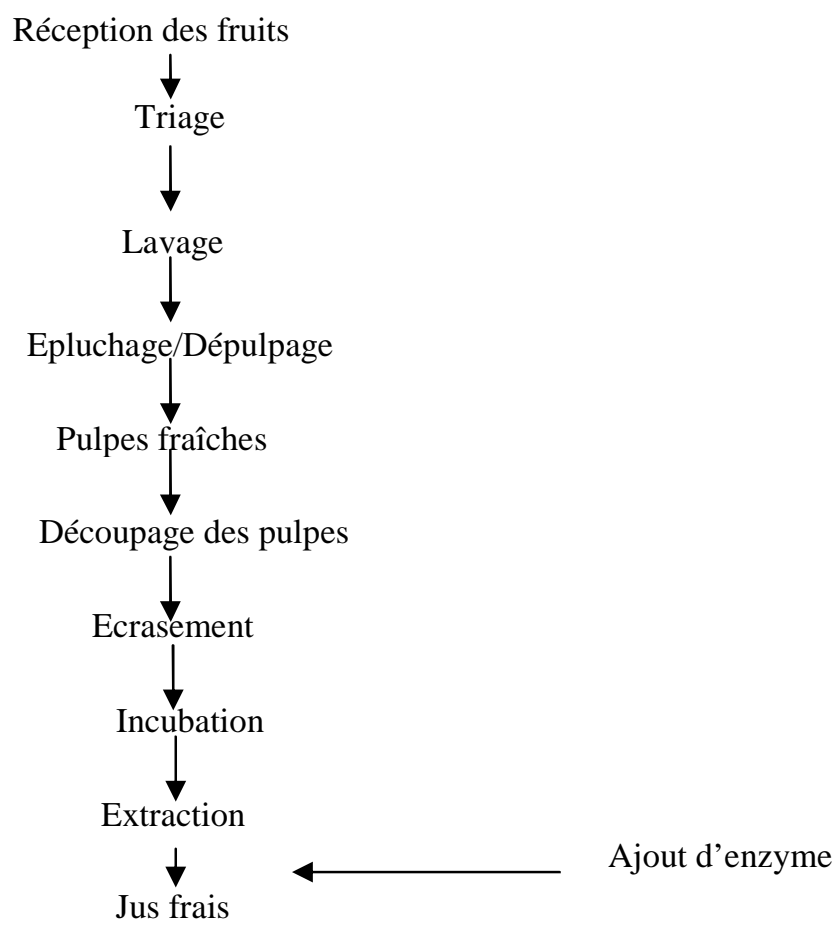

Figure 1: Diagramme de production du jus de la pulpe fraîche du fruit de rônier.

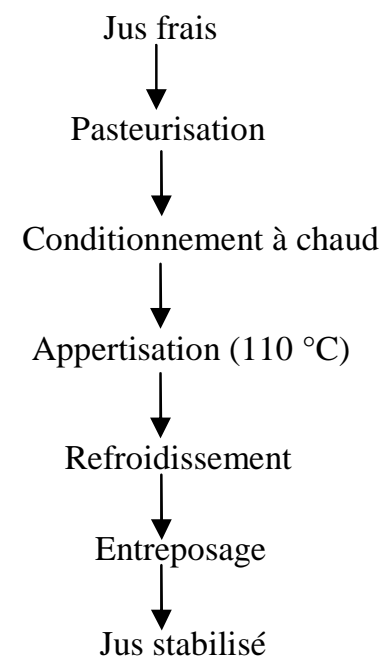

Figure 2 : Diagramme de stabilisation du jus de la pulpe fraîche du fruit de rônier.

\section{Recherche des Staphylocoques}

La technique d'étalement en surface de $0,1 \mathrm{ml}$ d'inoculum (échantillon et dilutions décimales) sur le milieu Baird Parker complet réalisée en duplicata a été utilisée. L'incubation des milieux ensemencés a été faite à $37{ }^{\circ} \mathrm{C} / 48$ heures. Les colonies caractéristiques noires brillantes entourées d'halo clair ont été dénombrées; puis repiquées sur Chapman suivis de coloration de Gram. Parallèlement, d'autres colonies ont été ensemencées dans $5 \mathrm{~mL}$ de Bouillon Coeur Cervelle $(\mathrm{BCC})$ et incubées à $37{ }^{\circ} \mathrm{C}$ pendant 24 heures pour le test de la coagulase. La 
réalisation du test a consisté au mélange dans un rapport de $1 / 3$ respectivement pour le $\mathrm{BCC}$ ensemencé et le sérum de lapin, le tout a été incubé à $37^{\circ} \mathrm{C}$ pendant 6 heures; la première lecture a été faite 3 heures après. Les tubes positifs correspondent à une prise en masse du contenu. La méthode utilisée est celle décrite par la norme NF EN ISO 6888-1.

\section{Recherche des spores d'anaérobies sulfito- réducteurs}

La recherche des spores d'anaérobies sulfito-réducteurs permet d'évaluer les risques de toxi-infection à Clostridium. Le milieu de culture utilisé est Tryptone Sulfite Néomycine (TSN). La méthode utilisée est le dénombrement en anaérobiose des bactéries sulfito-réducteurs décrite par la norme NF V 08-061.

\section{Recherche des Salmonella}

La recherche des Salmonella dans les aliments comporte des étapes essentielles à savoir : le préenrichissement, l'enrichissement, l'isolement et la confirmation. La méthode utilisée pour cette recherche est celle spécifiée par la norme NF V 08-052.

\section{Analyse sensorielle}

L'appréciation des caractères sensoriels des différents jus a été réalisée par la méthode NF V09-002 à partir d'une fiche technique préétablie et un jury constitué de dix testeurs sélectionnés selon leur aptitude à déterminer les goûts sucré, amer et acide, les couleurs et les arômes et ayant aussi une connaissance parfaite du fruit mûr de rônier.

\section{Analyses statistiques}

Les résultats ont été analysés statistiquement par la méthode de variance (ANOVA) à l'aide du logiciel STATISTICA (Stat., Soft, Inc., 1995). La comparaison des moyennes de trois essais est effectuée par le test de la plus petite différence significative LSD (Least Significant Difference). Cette méthode d'analyse consiste à chercher les moyennes qui diffèrent significativement les unes des autres. Les différences sont significatives lorsque $\mathrm{p}<0,05$.

\section{RESULTATS \\ Rendements d'extraction}

Les Figures 3 et 4 présentent les rendements obtenus à l'extraction des jus. Les résultats obtenus montrent que le rendement moyen à l'extraction du jus sans utilisation d'enzyme n'est nullement influencé par la température et est de 20,6\%. Par contre, on note une augmentation du rendement au niveau des jus extraits au moyen d'enzymes. Cette augmentation varie en fonction de la température et du temps d'incubation. Les meilleurs rendements sont obtenus à $50{ }^{\circ} \mathrm{C}$ après $120 \mathrm{~min}$ d'incubation et sont respectivement de $79,8 \%$ et $78,4 \%$ pour le jus extrait avec la Rapidase press et la Klerzyme120.

\section{Caractéristiques des jus frais}

Les jus frais obtenus ont une couleur rose-orangée, odorants avec une fragrance douce et florale du rônier mûr et légèrement visqueux. Ils sont modérément sucrés avec une faible amertume caractéristique du fruit.

Les résultats de l'évaluation de l'acidité de ces jus sont présentés dans le Tableau 2. Ces résultats montrent que les jus frais extraits au moyen de pectinases ont une acidité élevée, d'environ 1,6 g/l contre $0,64 \mathrm{~g} / \mathrm{l}$ pour le jus extrait sans enzyme. Ces résultats sont également confirmés par les $\mathrm{pH}$ des jus frais extraits sans utilisation d'enzyme qui sont compris entre 4,4 à 4,9 (Tableau 2). Par contre, les pH des jus extraits avec enzyme sont plus bas $(3,4$ à 3,8$)$. Les différentes teneurs en sucres totaux des jus extraits sont présentées dans le Tableau 3. Ces teneurs varient entre 9,71 et $9,87 \mathrm{~g} / \mathrm{l}$ dans le jus extrait sans enzyme contre à $17,81 \mathrm{~g} / 1$ pour les jus extraits avec enzyme.

Les jus frais obtenus ont une charge microbienne élevée caractérisée par la présence de coliformes, des levures et moisissures et des spores de germes anaerobies sulfito-réducteurs (Tableau 5). Ces résultats indiquent l'importance d'un traitement thermique du jus afin de réduire de façon substantielle sa charge microbienne et le rendre stable au cours de la conservation. 


\section{Caractéristiques des jus stabilisés}

L'évaluation de l'effet des traitements technologiques sur les paramètres physicochimiques des jus stabilisés, a permis d'obtenir les résultats présentés dans le Tableau 4. L'analyse de ces résultats révèle que les traitements thermiques appliqués ont très peu modifié le $\mathrm{pH}$, l'acidité titrable, les teneurs en matières sèches, sucres totaux. On note par contre une diminution de la teneur en caroténoïdes des jus après traitement.

Les résultats obtenus à l'issu de l'évaluation de la qualité hygiénique et sanitaire des jus de rônier extraits au moyen de pectinases sont présentés dans le Tableau 5. En comparant les résultats obtenus à la réglementation française, qui indique que la flore mésophile aérobie, quel que soit l'aliment, doit être inférieure à $10^{6}$ germes dont tout au plus $10^{2}$ et $10^{3}$ germes pour les coliformes fécaux et les staphylocoques respectivement, et une absence de germes pathogènes, les résultats des analyses microbiologiques montrent que les jus stabilisés sont de qualité satisfaisante par rapport aux germes témoins de contamination fécale et cutanéo-muqueuses.

Les tests organoleptiques ont révélé que les jus conservent leur flaveur avec la subtile fragrance douce et florale du rônier mûr et une couleur orangée avec une absence de 'goût de cuit'.

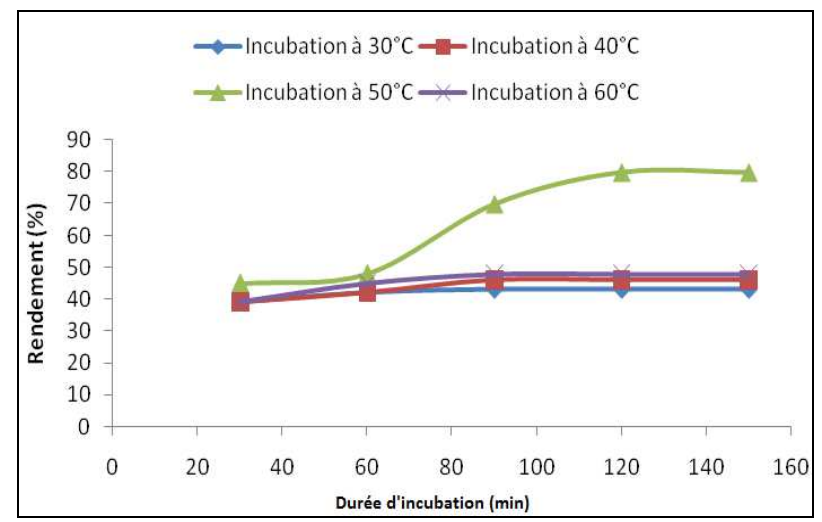

Figure 3: Evolution du rendement en jus extraits à différentes températures avec la Rapidase Press.

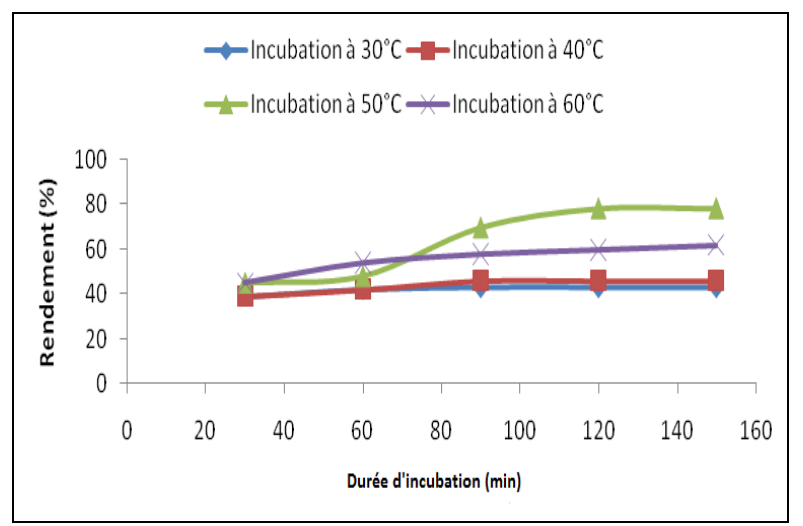

Figure 4: Evolution du rendement en jus extraits à différentes températures avec la Klerzyme 120. 
Tableau 1 : Acidité titrable des jus exprimée en g/l.

\begin{tabular}{|c|c|c|c|c|c|c|c|c|c|}
\hline Type d'extraction & \multicolumn{3}{|c|}{ Extraction avec Rapidase press } & \multicolumn{3}{|c|}{ Extraction avec klerzyme 120} & \multicolumn{3}{|c|}{ Extraction sans enzyme } \\
\hline $\begin{array}{l}\text { Temps d'incubation } \\
\text { (min) }\end{array}$ & 30 & 60 & 120 & 30 & 60 & 120 & 30 & 60 & 120 \\
\hline Incubation à $30^{\circ} \mathrm{C}$ & $1,3 \pm 0,1 \mathrm{a}$ & $1,36 \pm 0,1 \mathrm{a}$ & $1,28 \pm 0,0 \mathrm{a}$ & $1,17 \pm 0,1 \mathrm{a}$ & $1,36 \pm 0,1 \mathrm{a}$ & $1,52 \pm 0,3 a$ & $0,64 \pm 0,0 \mathrm{a}$ & $0,64 \pm 0,0 \mathrm{a}$ & $0,64 \pm 0,0 \mathrm{a}$ \\
\hline Incubation à $40^{\circ} \mathrm{C}$ & $1,2 \pm 0,6 b$ & $1,12 \pm 0,1 b$ & $1,20 \pm 0,0 \mathrm{a}$ & $1,08 \pm 0,1 \mathrm{a}$ & $1,20 \pm 0,0 b$ & $1,20 \pm 0,2 b$ & $0,65 \pm 0,0 \mathrm{a}$ & $0,66 \pm 0,0 \mathrm{a}$ & $0,64 \pm 0,0 \mathrm{a}$ \\
\hline Incubation à $50^{\circ} \mathrm{C}$ & $1,28 \pm 0,5 b$ & $1,33 \pm 0,0 \mathrm{a}$ & $1,6 \pm 0,1 b$ & $1,310,04 b$ & $1,28 \pm 0,1 b$ & $1,52 \pm 0,1 \mathrm{a}$ & $0,64 \pm 0,0 \mathrm{a}$ & $0,63 \pm 0,0 \mathrm{a}$ & $0,65 \pm 0,0 \mathrm{a}$ \\
\hline Incubation à $60^{\circ} \mathrm{C}$ & $1,28 \pm 0,3 b$ & $1,28 \pm 0,2 \mathrm{c}$ & $1,36 \pm 0,1 \mathrm{c}$ & $1,20 \pm 0,1 \mathrm{a}$ & $1,20 \pm 0,1 b$ & $1,28 \pm 0,2 b$ & $0,64 \pm 0,0 \mathrm{a}$ & $0,64 \pm 0,0 \mathrm{a}$ & $0,64 \pm 0,0 \mathrm{a}$ \\
\hline
\end{tabular}

Les valeurs portant la même lettre dans la même colonne ne sont pas significativement différents $(\mathrm{p}<0,05)$

Tableau 2 : Evolution du pH des jus extraits.

\begin{tabular}{|c|c|c|c|c|c|c|c|c|c|}
\hline \multirow{2}{*}{$\begin{array}{l}\text { Type d'extraction } \\
\text { Temps d'incubation } \\
\text { (min) }\end{array}$} & \multicolumn{3}{|c|}{ Extraction avec Rapidase press } & \multicolumn{3}{|c|}{ Extraction avec klerzyme 120} & \multicolumn{3}{|c|}{ Extraction sans enzyme } \\
\hline & 30 & 60 & 120 & 30 & 60 & 120 & 30 & 60 & 120 \\
\hline Incubation à $30^{\circ} \mathrm{C}$ & $3,70 \pm 0,24 a$ & $3,65 \pm 0,24 a$ & $3,80 \pm 0,43 \mathrm{a}$ & $3,60 \pm 0,16 a$ & $3,70 \pm 0,17 \mathrm{a}$ & $3,60 \pm 0,24 a$ & $4,55 \pm 0,12 \mathrm{a}$ & $4.37 \pm 0,46 \mathrm{a}$ & $4.35 \pm 0,46 a$ \\
\hline Incubation à $40^{\circ} \mathrm{C}$ & $3,67 \pm 0,11 \mathrm{a}$ & $3,72 \pm 0,23 b$ & $3,72 \pm 0,17 \mathrm{~b}$ & $3,72 \pm 0,34 b$ & $3,87 \pm 0,21 b$ & $3,80 \pm 0,23 b$ & $4,53 \pm 0,14 \mathrm{a}$ & $4.35 \pm 0,42 \mathrm{a}$ & $4.33 \pm 0,42 \mathrm{a}$ \\
\hline Incubation à $50^{\circ} \mathrm{C}$ & $3,56 \pm 0,45 b$ & $3,67 \pm 0,29 a$ & $3,58 \pm 0,36 \mathrm{c}$ & $3,56 \pm 0,23 \mathrm{a}$ & $3,65 \pm 0,28 \mathrm{a}$ & $3,56 \pm 0,31 \mathrm{a}$ & $4,56 \pm 0,11 \mathrm{a}$ & $4.38 \pm 0,43 \mathrm{a}$ & $4.35 \pm 0,43 a$ \\
\hline Incubation à $60^{\circ} \mathrm{C}$ & $3,50 \pm 0,3 b$ & $3,60 \pm 0,17 \mathrm{a}$ & $3,60 \pm 0,25 \mathrm{c}$ & $3,64 \pm 0,30 \mathrm{c}$ & $3,43 \pm 0,43 c$ & $3,53 \pm 0,35 \mathrm{a}$ & $4,55 \pm 0,15 \mathrm{a}$ & $4.37 \pm 0,41 \mathrm{a}$ & $4.36 \pm 0,41 \mathrm{a}$ \\
\hline
\end{tabular}


E. S. ADJOU et al. / Int. J. Biol. Chem. Sci. 7(3): 1135-1146, 2013

Tableau 3 : Evolution de la teneur en sucres totaux (g/L) des jus extraits.

\begin{tabular}{|c|c|c|c|c|c|c|c|c|c|}
\hline \multirow{2}{*}{$\begin{array}{l}\text { Type d'extraction } \\
\text { Temps d'incubation (min) }\end{array}$} & \multicolumn{3}{|c|}{ Extraction avec Rapidase press } & \multicolumn{3}{|c|}{ Extraction avec klerzyme 120} & \multicolumn{3}{|c|}{ Extraction sans enzyme } \\
\hline & 30 & 60 & 120 & 30 & 60 & 120 & 30 & 60 & 120 \\
\hline Incubation à $30{ }^{\circ} \mathrm{C}$ & $12,9 \pm 0,2 \mathrm{a}$ & $15,65 \pm 0,1 \mathrm{a}$ & $11,87 \pm 0,3 \mathrm{a}$ & $17,54 \pm 0,4 a$ & $15,38 \pm 0,2 \mathrm{a}$ & $15,38 \pm 0,3 \mathrm{a}$ & $9,71 \pm 0,3 \mathrm{a}$ & $9,71 \pm 0,5 a$ & $9,81 \pm 0,2 \mathrm{a}$ \\
\hline Incubation à $40^{\circ} \mathrm{C}$ & $12,7 \pm 0,1 \mathrm{a}$ & $17,81 \pm 0,3 \mathrm{a}$ & $16,73 \pm 0,0 b$ & $14,84 \pm 0,2 b$ & $17,27 \pm 0,1 \mathrm{~b}$ & $13,76 \pm 0,2 b$ & $9,74 \pm 0,1 \mathrm{a}$ & $9,74 \pm 0,2 \mathrm{a}$ & $9,84 \pm 0,5 \mathrm{a}$ \\
\hline Incubation à $50{ }^{\circ} \mathrm{C}$ & $16,19 \pm 0,0 \mathrm{~b}$ & $12,95 \pm 0,6 b$ & $14,84 \pm 0,4 \mathrm{c}$ & $14,84 \pm 0,1 \mathrm{~b}$ & $13,49 \pm 0,4 \mathrm{c}$ & $14,30 \pm 0,3 b$ & $9,75 \pm 0,4 \mathrm{a}$ & $9,75 \pm 0,7 \mathrm{a}$ & $9,85 \pm 0,1 \mathrm{a}$ \\
\hline Incubation à $60^{\circ} \mathrm{C}$ & $15,65 \pm 0,1 b$ & $13,76 \pm 0,2 \mathrm{c}$ & $15,38 \pm 0,2 \mathrm{c}$ & $17,62 \pm 0,3 a$ & $15.65 \pm 0,3 a$ & $16,73 \pm 0,1 \mathrm{C}$ & $9,77 \pm 0,6 \mathrm{a}$ & $9,77 \pm 0,1 \mathrm{a}$ & $9,87 \pm 0,3 a$ \\
\hline
\end{tabular}

Les valeurs portant la même lettre dans la même colonne ne sont pas significativement différents $(\mathrm{p}<0,05)$.

Tableau 4 : Paramètres physico-chimiques des jus frais et stabilisé.

\begin{tabular}{lcc}
\hline Paramètres & Jus frais & Jus stabilisé \\
\hline $\mathrm{pH}$ & $3,58 \pm 0,41 \mathrm{a}$ & $3,57 \pm 0,12 \mathrm{a}$ \\
Acidité titrable $(\mathrm{g} / \mathrm{l})$ & $1,6 \pm 0,2 \mathrm{a}$ & $1,59 \pm 0,52 \mathrm{a}$ \\
Matière sèche $(\%)$ & $7,98 \pm 0,18 \mathrm{a}$ & $7,96 \pm 0,21 \mathrm{a}$ \\
Cendres $(\%)$ & $0,43 \pm 0,01 \mathrm{a}$ & $0,42 \pm 0,05 \mathrm{a}$ \\
Sucres totaux $(\%)$ & $14,84 \pm 0,37 \mathrm{a}$ & $14,82 \pm 0,91 \mathrm{a}$ \\
Caroténoïdes $(\mathrm{g} / 100 \mathrm{~g})$ & $1,15 \pm 0,41 \mathrm{a}$ & $0,494 \pm 0,01 \mathrm{~b}$ \\
Vitamines C $(\mathrm{g} / \mathrm{l})$ & $0,5 \pm 0,01 \mathrm{a}$ & $0,48 \pm 0,07 \mathrm{a}$ \\
Magnésium $($ méq.g/l) & $0,136 \pm 0,017 \mathrm{a}$ & $0,136 \pm 0,017 \mathrm{a}$ \\
Calcium (méq.g/l) & $0,144 \pm 0,011 \mathrm{a}$ & $0,144 \pm 0,019 \mathrm{a}$ \\
Potassium (méq.g/l) & $0,23 \pm 0,01 \mathrm{aa}$ & $0,27 \pm 0,019$ \\
Sodium (méq.g/l) & $2,2 \pm 0,6 \mathrm{a}$ & $2,2 \pm 0,4 \mathrm{a}$ \\
\hline \multicolumn{2}{c}{ Les valeurs portant la même lettre sur la même ligne ne sont pas significativement différentes $(\mathrm{p}<0,05)}$.
\end{tabular}


Tableau 5: Caractéristiques microbiologiques des jus.

\begin{tabular}{lccc}
\hline Paramètres & Jus frais & Jus stabilisés & $\begin{array}{c}\text { Critères microbiologiques } \\
\text { (U.E. 2005) }\end{array}$ \\
\hline Flore totale à $30^{\circ} \mathrm{C}$ & $>300 \mathrm{ufc} / \mathrm{ml}$ & $29 \mathrm{ufc} / \mathrm{ml}$ & - \\
Coliformes totaux & $12 \mathrm{ufc} / \mathrm{ml}$ & Absence & $10 \mathrm{ufc} / \mathrm{ml}$ \\
Coliformes thermotolérants & $8 \mathrm{ufc} / \mathrm{ml}$ & Absence & $10 \mathrm{ufc} / \mathrm{ml}$ \\
Levures et moisissures & $>300 \mathrm{ufc} / \mathrm{ml}$ & Absence & Absence \\
Anaérobies sulfito réducteurs & $6 \mathrm{ufc} / \mathrm{ml}$ & Absence & Absence \\
Staphylocoques à coagulase positive & Absence & Absence & Absence \\
Salomella Spp & Absence & Absence & Absence \\
\hline
\end{tabular}

U.E : Union Européenne.

\section{DISCUSSION}

Les enzymes sont de plus en plus utilisées dans l'industrie alimentaire à cause de leurs propriétés biologiques intéressantes. Les investigations sur l'efficacité des pectinases (hydrolases) dans l'extraction des jus de fruit en général ont montré que l'activité pectinolytique des enzymes accroît la destruction des parois cellulaires des pulpes et assure une meilleure extraction des jus (Prathyusha et Suneetha, 2011). Nos résultats concordent avec ceux observés par d'autres auteurs pour l'extraction enzymatique des jus de fruit (Agbo et Simard, 1992 ; Ezoua et al., 1999). L'évaluation des paramètres physicochimiques des jus a révélé une augmentation de l'acidité des jus extraits au moyen de pectinase. Cette élévation de l'acidité titrable pourrait être due à la libération des molécules d'acide galacturonique lors de l'hydrolyse des macromolécules sous l'action des pectinases. Cette observation se trouve aussi confirmée par les faibles acidités des jus extraits sans enzyme. Ces résultats sont conformes à ceux observés par Joshi et al. (1991), Agbo et Simard (1992) et Drilleau (1994). De même, la mesure du $\mathrm{pH}$ des jus de fruits est très importante, surtout pour les jus destinés à la conservation. Ainsi, le Codex Alimentarus recommande dans ce cas une valeur de $\mathrm{pH}$ comprise entre 3 et 4,5 pour les jus destinés à la conservation. Les valeurs de $\mathrm{pH}$ obtenues dans les jus frais extraits sans utilisation d'enzyme sont comprises entre 4,4 et 4,9. Ces valeurs de $\mathrm{pH}$ posent, comme indiqué plus haut, un problème de conservation de ce jus en l'état à cause des risques de fermentation. Par contre, les $\mathrm{pH}$ des jus extraits avec enzyme sont plus bas (3,4 à 3,8). La teneur en sucres totaux dans le jus obtenu sans utilisation de pectinases est inférieure à celle obtenue avec utilisation de pectinase. Les teneurs en sucres totaux varient très peu d'une enzyme à une autre. L'augmentation de la teneur en sucres totaux dans les jus extraits au moyen de pectinases pourrait aussi être due à l'activité pectinolytique des enzymes qui fragilisent la structure pariétale et libèrent le contenu cellulaire sous l'action de la presse.

Ces mêmes observations ont été confirmées par Agbo et Simard (1992) et Ezoua et al. (1999) dans la production du jus de rônier en utilisant une enzyme pectinolytique (Ultra pectinex). Cette teneur en sucres totaux est légèrement inférieure à celle obtenue dans le jus d'orange (12.3\%) (Hendrix et Redd, 1995). Ces résultats montrent que l'utilisation des enzymes dans l'extraction du jus de rônier améliore aussi significativement la teneur en sucres totaux 
dans les jus $(\mathrm{P}<0,05)$. Les traitements technologiques appliqués au jus en vue de sa stabilisation visent à obtenir des jus conservables à température ambiante au cours du temps. L'évaluation des paramètres physico-chimiques des jus stabilisés a cependant indiqué une légère réduction de la teneur en caroténoïdes dans le jus. Cette diminution d'environ $4,3 \%$ serait essentiellement due au caractère thermosensible des molécules de caroténoïdes. En effet, les caroténoïdes, localisés à l'intérieur des membranes internes sont peu sensibles à la chaleur, mais sensibles aux oxydations enzymatiques, chimiques et photochimiques (Cheftel et al., 1983).

Ils sont de ce fait assez stables et peu affectés par les traitements thermiques modérés lorsqu'ils sont tenus éloignés des enzymes oxydases. Par contre, si l'intégrité cellulaire est compromise et la membrane perméabilisée par épluchage, ou découpage, ils deviennent accessibles et vulnérables. Ils sont d'autant plus détruits que les traitements sont sévères et que leur concentration est élevée (Essiben, 2005). L'évaluation de la qualité microbiologique des jus stabilisés indique aussi que les technologies de production et de stabilisation utilisées sont efficaces et permettent d'obtenir un jus de qualité hygiénique satisfaisante par rapport aux germes précités. L'absence de germes pathogènes (Salmonella spp) indique qu'il n'y a aucun risque sanitaire avéré pour le consommateur. En effet, hormis les risques d'intoxination ou de toxi-infection associés à la présence de certains germes pathogènes dans les denrées alimentaires, les germes fermentaires sont essentiellement responsables de l'altération de la qualité marchande des aliments. Ces germes fermentaires dégradent les sucres fermentescibles avec production d'alcool, d'acide ou de métabolites indésirables. Ainsi, leur absence dans le jus de rônier stabilisé confère donc à ce produit une forte aptitude à la conservation. La qualité organoleptique des jus constitue aussi un facteur important dans l'appréciation de la qualité marchande des jus de fruits. La flaveur fraîche et la subtile fragrance douce et florale notées dans les jus de rônier pourraient être dues aux composés aromatiques contenus dans ce jus. En effet, plusieurs études ont démontré les effets de la chaleur notamment sur les composés volatiles contenus dans les jus de fruit. Les travaux de Bazemore et al. (1999) ont montré que l' $\alpha$-terpineol et le terpinen-4-ol sont des composés volatils synthétisés lors des traitements thermiques et responsables de l'arôme "oxydé" et " cuit" du jus d'orange. L'accentuation de l'arôme dans les jus peut être aussi corrélée à leur teneur en acide organique. En effet, l'acide citrique est une molécule hautement polaire qui contient trois groupements carboxyliques et un groupement hydroxylé. Sa forme dissociée dans des solutions aqueuses est considérablement réactive vis-à-vis des composés volatils. Hansson et al. (2001) ont observé que la libération d'un composé volatil, tel que le limonène ou de certains esters comme l'ethyl hexanoate, à partir d'une solution aqueuse vers la phase vapeur, est modifiée par les variations de la concentration d'acide citrique dans cette solution. Ainsi, à faibles concentrations $(0,2 \mathrm{~g} / \mathrm{l})$, l'acide citrique favorise la diffusion des composés volatils vers la phase vapeur. Ces observations justifient alors l'accentuation de l'arôme car les jus extraits au moyen de pectinases ont une acidité titrable d'environ 1,6 g/L exprimée en acide citrique. De même, les sels minéraux contribuent à la flaveur des jus de fruit. Leland (1997), a observé une corrélation significative entre la teneur en potassium et le degré de préférence d'un jus par les consommateurs. Selon cet auteur, les sels de potassium facilitent le relargage des composés volatils de la phase aqueuse vers la phase vapeur. 


\section{Conclusion}

L'utilisation des enzymes a permis d'augmenter de façon considérable le rendement à l'extraction des jus. Le rendement le plus élevé est obtenu avec la Rapidase press à une température de $50{ }^{\circ} \mathrm{C}$ après $120 \mathrm{~min}$ d'incubation. Les enzymes utilisées améliorent également les caractéristiques physico-chimiques du jus. Les traitements technologiques de stabilisation appliqués, permettent d'obtenir un jus non fermenté, hygiénique, stable (absence de germes d'altération) et qui conserve une saveur et un arôme caractéristique du fruit. Le traitement à la chaleur a permis aussi de réduire substantiellement son activité enzymatique et le nombre de microorganismes viables. La caractérisation des minéraux dans le jus a montré la présence de $\mathrm{Ca}, \mathrm{Mg}, \mathrm{K}$ et $\mathrm{Na}$ avec une teneur relativement élevée en Sodium (Na). Cette étude a permis de mettre au point un procédé efficace de production du jus de rônier au moyen des pectinases.

\section{REMERCIEMENTS}

Les auteurs remercient sincèrement la Faculté des Sciences et Techniques et l'Ecole Polytechnique de l'Université d'Abomeycalavi pour leur soutien financier dans la réalisation de ce travail.

\section{REFERENCES}

Ali A, Alhadji D, Tchiegang C, Saidou C. 2010. Physico-chemical properties of Palmyra palm (Borassus aethiopum Mart.) fruits from Northern Cameroon. J. Food Sci., 4(3): 115-119.

Agbo NG, Simard RE. 1992. Characteristics of Juice from Palmyrah palm (Borassus aethiopum Mart.). Plant Foods Hum. Nutr., 42: 55-70.

AOAC. 1990. Official Methods of Analysis, (15th Edn). Association of Official Analytical Chemists: Washington DC.; $774 \mathrm{p}$.
Bayton RP, Ouedraogo A, Guinko S. 2006. The genus Borassus (Arecaceae) in West Africa, with a description of a new species from Burkina Faso. Bot. J. Linnean Soc., 150: 419-427.

Bazemore R, Goodner K, Rousseff R. 1999. Volatiles from Unpasteurized and Excessively Heated Orange Juice Analyzed with Solid Phase Microextraction and GC-Olfactometry. $J$. Food Sci., 64(5): 800-803.

Cheftel JC, Cheftel H, Besancon P. 1983. Introduction à la Biochimie et à la Technologie des Aliments (Vol.1). Edition Technique et Documentation, Lavoisier : Paris ; 420.

Drilleau JF. 1994. Biochemical characteristics of apple juices and fermented products from musts obtained enzymatically. Fruit Processing, 4: 108-113.

Essiben YC. 2005. Influence d'une déshydratation par entraînement après blanchiment sur les teneurs en carotène et vitamine C : cas Dioscorea Schimperiana, Mémoire de Maîtrise, Université de Douala Cameroun, 87 p.

Ezoua P, Kouamé D, Agbo NG. 1999. Caractéristique du jus de la pulpe fraîche $\mathrm{du}$ fruit de rônier (Borassus aethiopum Mart). Cahiers Agr., 8: 126-128.

FAO. 1994. Situation de la Sécurité Alimentaire Mondiale et Evolution Récente des Politiques. CFS: Rome.

Houankoun-Daannon E. 2005. Importance socio-économique du rônier (Borassus aethiopum): Différents usages et commercialisation de quelques sousproduits au Bénin. Mémoire de DEA, Option Gestion de l'Environnement, Faculté des Lettres Arts et Sciences Humaines (FLASH), Université d'Abomey-Calavi (Bénin).

Hansson A, Andersson J, Leufven A, Penrson K. 2001. Effect of changes in $\mathrm{pH}$ on the Release of Flavour Compounds from a 
Soft Drink-Related Model System. Food Chem., 74(4): 429-435.

Hendrix CM, Redd JB. 1995. Chemistry and Technology of Citrus Juices and ByProducts. In Production and Packaging of Non-Carbonated Juices and Fruit Beverages Ashurst PR (ed). Blackie Academic \& Professional; 53-87.

Joshi VK, Chauhan SK, Lal BB. 1991. Extraction of juices from peaches, plums and apricots by pectinolytic treatment. $J$. Food Sci. Technol., 28(1): 64-65.

Leland JV. 1997. Flavor interactions: the great whole. Food Technology, 51(1): 75-80.
Prathyusha K, Suneetha V. 2011. Bacterial pectinases and their potent biotechnological application in fruit processing/juice production industry: a review. J. Phythology, 3(6): 16-19.

Pourmaghi-Azar MH, Ojani R. 1997. A selective catalytic voltammetric determination of vitamin $\mathrm{C}$ in pharmaceutral preparations and complex matrices of fresh fruit juices. Talanta, 44: 297-303. 